\title{
Kapati Time: Storytelling as a Data Collection Method in Indigenous Research
}

\author{
Robyn Ober \\ Batchelor Institute of Indigenous Tertiary Education \\ robyn.ober@batchelor.edu.au
}

Keywords: Aboriginal English, Indigenous knowledges, Indigenous research methodologies, storytelling, both-ways.

\begin{abstract}
There is currently a strong movement among First Nations researchers in Australia and globally to draw on their own epistemologies, ontologies and axiologies in academic research. It is evident that Indigenous researchers are pushing back the boundaries in the research academy to make space for a new, fresher way to do research by drawing on old traditional Indigenous ways. Our Indigenous ways of working, being and making-meaning appeal to me as a researcher, because these are my strength, these are familiar to me, these are what I know. By drawing on my own epistemologies, ontologies and axiologies, I am bringing my own thought process, ethical considerations, and culturally appropriate ways of carrying out research with Aboriginal and Torres Strait people.
\end{abstract}

\section{Introduction}

This paper will explore the place and space of storytelling in my current $\mathrm{PhD}$ research study titled, Aboriginal English as an Academic Discourse in Indigenous Tertiary Education. This is a qualitative study exploring the role of Aboriginal English as a cultural and identity marker and contributor to academic discourse in tertiary educational teaching and learning spaces.

Aboriginal English as a dialect of English, is now recognized as the first language of many Aboriginal Australians. This form of communication is rich, highly structured and a complex form of the English language, and it is widely appropriated in the social and cultural domains of Aboriginal people. (Ober \& Bell, 2012, p. 60)

Storytelling or 'yarning' is embedded within the processes and structure of Aboriginal society. Stories are empowering and uplifting, giving access to layers of deep cultural and historical knowledge that make up the social and cultural identity of Aboriginal people. In this paper I will discuss the process and the purpose of using stories as part of my research methodology, drawing on the 'narrative enquiry' approach which I found to be more culturally inclusive and relevant to Aboriginal ways of being, doing and knowing.

\section{Stories in Aboriginal Families}

For many Aboriginal people, storytelling is often referred to as 'yarning', where people gather informally to relax and reflect on stories in recent or past history. Storytelling is also about creativity, it is where people come together to share knowledge through retelling, re-presenting 
and creating new stories through new experiences, new people and new places. Significant family histories and old stories are retold in new ways as a way to bring greater understanding to younger family members who are still learning their social and cultural identity.

Aboriginal people often use humour to tell light-hearted stories, to retell a funny event, or even to show a comical side of a serious topic. Stories are often used to teach about cultural morals, behaviour, boundaries, rules, attitudes and values. In my own family I have observed my elders sharing short sharp oral recounts to guide younger members in culturally appropriate behaviour in particular social settings.

As Aboriginal families are traditionally quite large, they often have their own story tellers who are effective communicators within the social group. There are identified people who can retell stories in a unique way which totally captures the message, emotion, characters, morals or punchline of the story. When I think about 'yarning', I think about what I refer to in my family as 'kapati' (cup of tea) time. This is usually when family members (young and old) gather together for a kapati, a meal or feast. This is part of our family's social engagement, interaction and the strengthening of kinship ties. There is something good, exciting and appealing about coming together as a family, but this is also true about coming together to tell stories. Kapati time in my family is really about making the space and time for social interaction in a culturally appropriate and safe way. The process of knowledge sharing is through family members interacting through negotiation, disagreement, debating and arguing within the kapati space. Topics of conversation can vary from reflections of the past, current family news, family gossip, sad news and celebrations. Music, song and dance are always a large part of Aboriginal family gatherings, where stories are also communicated through a fun, creative and enjoyable way.

I first became aware of the power, precision and purpose of storytelling in my family while undertaking a pilot study as part of the Masters in Applied Linguistics course. I had planned a structured interview with a set of eight specific questions related to miscommunication and misinterpretation within cross-cultural contexts. I had intended to interview a close family member to identify social, cultural and linguistic factors that lead to miscommunication and misinterpretation between Aboriginal and non-Aboriginal people. I carefully prepared my eight structured questions as part of the interview, anticipating a rich collection of data which would be recorded on the digital recorder. The following extract is from the 'Research Design' chapter of my PHD thesis, where I describe the discomforts experienced by an Aboriginal participant and myself as the researcher in the data collection phase.

I decided to interview a close older male family member. I chose to use the interview technique as the data collection method as this seemed to be a quick way of collecting the required information. We sat in the back yard of his house, and I proceeded to put on my researchers hat, changing my voice into an academic researcher which was totally foreign and strange to my participant. However, he continued trying to accommodate my requests as best he could. Ironically the pilot study was about 'miscommunication and misinterpretation between Aboriginal and non-Aboriginal people'. By the third question, he strongly stated with some aggressiveness, 'look I'll just tell you the story and you can work it out from there'. This last statement regarding stories led me to thinking about our ways of sharing important knowledge through stories as a research methodology.

Over the years I have reflected on this defining moment where I realised that there are alternative research methodologies that are a better fit for Aboriginal and Torres Strait Islander people rather than following a strictly western academic approach. 
As part of the pilot study for the Masters of Applied Linguistics course, I was required to reflect on the positives and negatives of the interview, evaluating the effectiveness of the process. The following is a summary of the interview process from my perspective as a researcher but also as an insider to the Aboriginal community and family social context.

The interview began quite well, with a clear recount of a family situation, where miscommunication occurred between hospital staff and the extended family of the informant. Although the beginning stages of the interview were smooth with information flowing easily, it gradually became evident that the participant began to struggle when asked to respond to the next question in isolation to the previous one. The participant seemed to be uncomfortable with the short, sharp response expected from the researchers questioning structure and technique. There seemed to be some resistance by the participant to make isolated comments against each question without referring to what was previously stated.

As a result, the participant found it easier to just openly share the critical incident, and then give me the opportunity in collaboration with him to search for appropriate responses to the five-set question. Once the obstacle of responding to specific questions was removed, it was obvious the participants verbal accounts of the critical incident flowed freely and richly with a touch of humour. The verbal and facial expressions as well as feelings and emotions replaced the uneasiness and awkwardness. (Ober, 2011, p. 4-5, GCIK Assessment Task 2)

Language was also an issue between myself as the researcher and the participant, given our first language is Aboriginal English, specifically the North Queensland (Murri) variety. Therefore, it was strange and unauthentic to speak a form of Standard Australian English (SAE) in the actual interview, as this form of English is rarely spoken in our home language environment.

This was a challenging experience and forced me to ask questions of myself as a researcher such as, how can we work with Aboriginal people in a way that is supportive, respectful and understanding of our ways of carrying out research?. There must be a better way to undertake research with our people, without being forced into a mode of working that causes all involved to become frustrated, confused and angry. I have decided that the common-sense approach is to be true to yourself, don't forget who you are, bring your whole self into the research domain, to ensure you are working in an ethical, authentic, genuine and respectful way.

\section{The Narrative Enquiry Approach}

As a data collection method, the narrative enquiry approach was used as a way to better engage with Aboriginal and Torres Strait Islander students in the research space. A narrative enquiry approach rests on the epistemological assumption that we as human beings make sense of random experience by the imposition of story structures (Bell, 2002, p. 207). In Australian Aboriginal societies, storytelling is a natural part of life; it is used to inform past histories, kinship structures, beliefs, values, morals, expected behavior and attitudes.

Story telling is a feature of Indigenous societies where oral traditions were the main form of transmitting and sharing knowledge with individuals and between groups. Through oral traditions information was passed down through the generations in the form of stories and songs. (Bessarab \& Ng'andu, 2010, p. 38) 


\section{The Kapati Method}

The Kapati (cup of tea) method of data collection draws on the narrative inquiry approach where participants' stories (individual and collective group) are collected and analysed to understand how participants (students) draw on their social, cultural and linguistic repertoire to make meaning of new professional knowledge. I have previously used the kapati approach in a project with Torres Strait Islander academic and cultural advisor, Noressa Bulsey, in the Both-ways in Action project (Ober \& Bulsey, 2011-2012). As we were both from similar cultural backgrounds and geographical locations, we understood the importance of social interactions in our families.

kapati times in our family are an important and often enjoyable event. It is a time for social interaction; this includes a time to laugh, cry, gossip, be angry, be reflective, and simply to celebrate our survival as an Indigenous race in a culturally supportive environment. (Ober \& Bat, 2007, p. 66)

As a child growing up, it was a common and expected practice for family members to invite visitors and extended family in for a kapati. Kapati time has become an integral cultural norm of Indigenous society, where the announcement of kapati signals yarn time. Yarn time means catching with family and community news, sharing stories, reflecting on the past, telling and retelling humorous stories; basically a time for strengthening family and kinship ties (Ober \& Bat 2007 p.66).

\section{Karpati in the East Kimberley}

Aboriginal researchers in the East Kimberley (Western Australia) have also used the 'cup of tea', approach. Horstman and Wightman (2001, p. 102) explain that 'karpati' with Traditional Owners invokes 'remote localities, tucker boxes, shady trees, boiling billies, storytelling, and making the time to discuss plants and animals, land and sea management and a range of related issues'.

When somebody calls, 'karpati!' while travelling through country, it is time to stop and discuss where we have just been, or plan where we go next. The reasons for stopping may not be immediately apparent to the researcher, but are always important to the custodians. (Horstman \& Wightman, 2001, p.103)

Social interaction and engagement is an important practice for Aboriginal families as I explain in a previous paper:

The need for social interaction over a kapati is embedded and intertwined within our social and cultural domain. We as family and community members have obligations, expectations, ethics, morals, roles and responsibilities that connect us to our culture. (Ober \& Bat, 2007, p.67)

Horstman and Wightman (2001) further explain that 'the karpati approach is based on guidance by the senior custodians, embraces respect, balance, reciprocity, flexibility and time availability and of course a pannikin or two of tea' (p.103).

In the Both-ways in Action project Noressa and I understood that there was great value in making the space for stories to be shared, not just for the sake of it, but to bring about a deeper understanding of professional constructs through Indigenous ways of making sense 
and meaning. By reflecting on our ways of sharing information in the home environment through storytelling around a kapati, we could then use a similar approach in the research space especially with Indigenous participants.

\section{Student Kapatis}

During the Both-ways in Action project I set up the kapati sessions with food, tea, coffee and water to re-create the home environment where Indigenous participants would be comfortable to converse and generate new knowledge. Noressa and I cooked chicken curry and chicken vermicelli with rice, damper and Johnnycakes to set the tone and mood for the kapati. We encouraged lots of social interaction ensuring everybody was at ease and relaxed in the kapati environment. Food brings laughter and humour, and lots of stories. This created a space where diverse voices, realities, truths and perspectives were shared in a culturally safe environment.

During the student kapatis in my current PhD study, I played excerpts from the video footage of classroom observations (from my research study) as a stimulus to encourage critical reflective discussion. I asked the following questions to stimulate conversation: what do you think is happening here? Why? What does it mean from a both-ways perspective? What counts? What doesn't count? How is this reflective of both-ways?

The purpose of this approach was to produce a richer, more authentic analysis as observed from the student participants themselves. Wilson (2008) states that, 'research from an Indigenous paradigm should aim to be authentic or credible' (p. 101). I wanted to see if the participants saw and heard the same things I did, or did they see and hear something completely different. We then collaboratively, explored why? I wanted validation or contradiction of the themes, big ideas, and topics emerging from the data that I had identified. What were students thinking about this overall topic of culture, identity, language and learning in a both-ways tertiary educational context?

In the student kapatis, I noticed participants spoke in metaphors to describe an idea or concept. Metaphors are using something familiar in your world to explain and describe an abstract phenomenon to others in your world. In regard to stories, Kovach, a Plains Cree and Saulteaux First Nations scholar, explains that:

Within the structure of story, there is space for the fluidity of metaphor, symbolism, and interpretative communications (both verbal and nonverbal) for a philosophy and language that is less definitive and categorical. My sense is that in the old days as now, the skilled orators were able to imbue energy through word choice, and allow the listener to walk inside the story to find their own teachings. (Kovach, 2005, p. 12)

For a listener to walk inside the story is to bring greater meaning, awareness and clarity to the messages, the philosophy, values and belief of the story being communicated. In thinking about elders in my family, there are underlying messages being shared with the family, sometimes directly but often indirectly where we are expected to read between the verbal lines, to understand the intended messages.

\section{The Guitar Metaphor}

In the postgraduate kapati, a senior elder who is also a postgraduate candidate described the importance of language and cultural identity through the metaphor of playing a guitar. $\mathrm{He}$ cleverly likened the strings on a guitar to the diverse language groups represented at Batchelor Institute including forms of English language, Creoles and dialects. 
If you look at those strings as people coming from different backgrounds, different language backgrounds or cultures see they come in from a knowledge base whether the string is small string or it's a big string - it might be a big tribe or might be small tribe, but they all important, they got that value of importance. And to tune that guitar - right to that deadly tune you want to sing - the singer, the player must recognise that. (Post Graduate Canditate 1, Postgraduate Kapati 12-08-14)

This research participant is emphasising that all languages are of equal importance, and each holds credibility and validity, regardless of its status, significance or positioning in the institute. I see this as a holistic view, that recognises SAE as just one of those strings on the guitar, but it holds no more or less importance than any of the other strings. In fact, depending on your social contextual environment, it may hold less, or no, importance than the other languages depending on where you are situated. For example, in Aboriginal and Torres Strait Islander communities where people strongly speak their own languages, SAE would hold little status, power or recognition unless used in formal contexts of Australian governance, or with organisations and service providers. This contrasts with SAE which is perceived as an elite language of power in most universities and educational institutions. Standard English brings an element of status, which implies other varieties of English are non-standard and therefore not valued or acknowledged. There is a mindset that, 'the acquisition of Standard English is considered to be one of the most important goals of formal education' (Siegal, 2014, p. 40). This may be true, but students' first languages also have a role to play in acquiring the second language or dialect of standard English.

The guitar metaphor provides a way of thinking about knowledge creation and production where knowledge holders are pushing the boundaries to incorporate both-ways teaching and learning in a real way. It is about working collaboratively and creatively knowing that everyone needs to contribute to create that deadly tune, whatever their language. The postgraduate participant is describing and articulating the linguistic repertoire of Aboriginal and Torres Strait Islander students in a way that makes sense from his social and cultural positioning.

The guitar metaphor, as described in the postgraduate kapati, is powerful in relation to the co-presence of diverse yet significant voices. This metaphor shows that for the majority of Indigenous Australians, cultural and linguistic diversity is normal, acceptable, and to be expected, and as such it is to be valued and respected without criticism and judgment. It is even more than this. It also needs to be positively valued as an asset that students bring with them to the learning experience.

\section{Conclusion}

As an Aboriginal researcher I hold the cultural knowledge of storytelling in our families and communities and because of this I have chosen the narrative enquiry methodology as the most relevant and culturally appropriate approach for collecting data in this study. Stories make knowledge accessible, alive and real for Aboriginal people as they embed Indigenous epistemologies and ontologies.

As an Aboriginal researcher I can't help but draw on my epistemologies and ontologies, our ways of being, knowing and thinking, because this is me. I'm in this research as an Aboriginal person who is seeking to engage with Aboriginal participants, and to do that I need to be true to myself and draw on our ways of doing things. I am trying to expand the space to converse, to explore, to engage with multiple voices, perspectives, ideas, thoughts, and truths. 
For Indigenous researchers, there is value in thinking about what we can learn from the home and community environment and bring into the teaching, learning and research space. We as Aboriginal and Torres Strait Islander people have a rich, diverse, creative and vibrant culture. We can reflect, we can embrace, and we can bring our ways of making meaning and making sense into the research space. It is my goal to be true to our ways of doing, being and knowing in the research space, but also to push and forge through into new, untouched knowledge bases in the domains of language, culture, identity and learning. The research space can at times become tumultuous and unsettled, but it's always moving, emerging and evolving to generate new cutting-edge knowledge if the right conditions and space are provided. 


\section{References}

Bell, J. S. (2002). Narrative Research in TESOL. Narrative Enquiry: More Than Just Telling Stories. TESOL Quarterly, 36(2), Toronto: York University.

Bessarab, D. \& Ng'andu, B. (2010). Yarning about yarning as a legitimate method in Indigenous research. International Journal of Critical Indigenous Studies, 3(1), 37-50.

Horstman, M. \& Wightman G. (2001). Karpati Ecology; recognition of Aboriginal Ecological knowledge and its application to management in north Western Australia. Ecological Management and Restoration, 2(2), 99-109.

Kovach, M. (2005). Emerging from the margins: indigenous methodologies. In L. Brown \& S. Strega (Eds.), Research As Resistance: Critical, Indigenous, and Anti-Oppressive (pp. 19-36). Toronto: Canadian Scholars' Press.

Ober, R. (2011). GCIK Assessment Task 2. Alice Springs: Batchelor Institute, 4-5.

Ober, R. (2014). Postgraduate Kapati. Unpublished transcripts. Alice Springs: Batchelor Institute.

Ober, R. \& Bat, M. (2007). Paper 1: Both-ways: the philosophy. Ngoonjook: Journal of Australian Indigenous Issues, (31), 64-86.

Ober, R. \& Bell, J. (2012). English Language as Juggernaut - Aboriginal English and Indigenous Languages in Australia. In V. Rapatahana \& P. Bunce (Eds.), English Language As Hydra - Its Impact On Non-English Language Cultures (pp. 60-75). Bristol: Multilingual Matters.

Siegal, J. (2006). Keeping Creoles and Dialects Out of the Classroom: Is It Justified? In S. J. Nero (Ed), Dialects, Englishes, Creoles and Education (pp. 39-67). New York: Routledge.

Wilson, S. (2008). Research is Ceremony: Indigenous Research Methods. Black Point: Fernwood Publications. 